\title{
Influence of cognitive functioning on functional status in an older population: 3- and 6-year follow-up of the Maastricht Aging Study.
}

Citation for published version (APA):

van Hooren, S. A. H., van Boxtel, M. P. J., Valentijn, A. M., Bosma, J. H. A., Ponds, R. W. H. M., \& Jolles, J. (2005). Influence of cognitive functioning on functional status in an older population: 3- and 6-year follow-up of the Maastricht Aging Study. International Journal of Geriatric Psychiatry, 20, 883-888. https://doi.org/10.1002/gps.1373

Document status and date:

Published: 01/01/2005

DOI:

10.1002/gps.1373

Document Version:

Publisher's PDF, also known as Version of record

Please check the document version of this publication:

- A submitted manuscript is the version of the article upon submission and before peer-review. There can be important differences between the submitted version and the official published version of record.

People interested in the research are advised to contact the author for the final version of the publication, or visit the DOI to the publisher's website.

- The final author version and the galley proof are versions of the publication after peer review.

- The final published version features the final layout of the paper including the volume, issue and page numbers.

Link to publication

\footnotetext{
General rights rights.

- You may freely distribute the URL identifying the publication in the public portal. please follow below link for the End User Agreement:

www.umlib.nl/taverne-license

Take down policy

If you believe that this document breaches copyright please contact us at:

repository@maastrichtuniversity.nl

providing details and we will investigate your claim.
}

Copyright and moral rights for the publications made accessible in the public portal are retained by the authors and/or other copyright owners and it is a condition of accessing publications that users recognise and abide by the legal requirements associated with these

- Users may download and print one copy of any publication from the public portal for the purpose of private study or research.

- You may not further distribute the material or use it for any profit-making activity or commercial gain

If the publication is distributed under the terms of Article 25fa of the Dutch Copyright Act, indicated by the "Taverne" license above, 


\title{
Influence of cognitive functioning on functional status in an older population: 3- and 6-year follow-up of the Maastricht Aging Study
}

\author{
Susan A. H. van Hooren ${ }^{1}$, Martin P. J. van Boxtel ${ }^{2,3}$, Susanne A. M. Valentijn ${ }^{4}$, Hans Bosma ${ }^{5}$, \\ Rudolf W. H. M. Ponds ${ }^{2}$ and Jelle Jolles ${ }^{2,3}$ \\ ${ }^{1}$ School of Psychology, Open University of the Netherlands, The Netherlands \\ ${ }^{2}$ European Graduate School of Neuroscience (Euron), Maastricht University, The Netherlands \\ ${ }^{3}$ Department of Psychiatry and Neuropsychology, Maastricht University, The Netherlands \\ ${ }^{4}$ Catharina Hospital, Eindhoven, The Netherlands \\ ${ }^{5}$ Department of Health Care Studies, Maastricht University, The Netherlands
}

\section{SUMMARY}

Background To date, it remains unclear to what extent cognitive competence is related to a change in general functional status in older adults.

Objectives To evaluate both the cross-sectional and the longitudinal relation between cognitive functioning and functional status.

Methods Sensorimotor speed, memory, and executive functioning were assessed in a large population of healthy adults aged 60 years and older $(n=485)$ who participated in the Maastricht Aging Study. Data from the baseline (1993-1995), three-year follow-up, and six-year follow-up were used. Functional status was measured using the SF-36, which was coded into a physical and a mental component summary measure.

Results After adjustment for age, sex, and educational level, a high level of cognitive functioning appeared to be associated with better functional status in the cross-sectional analysis. Longitudinal analyses demonstrated, that cognitive functioning was not a predictor of functional status three or six years later.

Conclusions Thus while cognitive functioning is useful clinically for predicting the short-term functional status of an older person, it is not useful for predicting that person's long-term ( $>3$ years) functional status and thus the period of validity of the results of these tests in answering such questions is limited. Copyright (C) 2005 John Wiley \& Sons, Ltd.

KEY WORDS - functional status; cognitive functioning; community dwelling older adults; aging

\section{INTRODUCTION}

In Western society, with its rapidly growing population of older individuals, it is important to identify functional limitations that could limit the autonomy

*Correspondence to: S. A. H. van Hooren, Open University of the Netherlands, School of Psychology, PO Box 2960, 6401 DL Heerlen, The Netherlands. Tel: $+31(0) 45$ 5762689. Fax: $+31(0) 45$ 5762939. E-mail: susan.vanhooren@ou.nl

Contract/grant sponsor: Dutch Research Council; contract/grant number: NWO 014-91-047.

Contract/grant sponsor: Dutch Ministries of Education and Health and Welfare via the Steering Committee for Gerontological Research (NESTOR). of older adults. Neuropsychologists are often asked to evaluate person's capabilities and limitations, and in many cases to answer questions concerning the functional status and consequences of cognitive limitations on daily life, such as a person's ability to take care of himself/herself and to manage his/her finances (Lezak, 1995; Barth et al., 2003). But how strong is the evidence that cognitive competence is actually associated with general functional status or autonomy? With a view to the increasing number of older adults and health care consumption, it is worthwhile to investigate in healthy old adults whether cognitive functions are associated with functional status. 
To date, several largely cross-sectional studies have provided some evidence that impaired cognitive functioning is associated with poor functional status (Richardson et al., 1995; Greiner et al., 1996; Gill et al., 1997; Grigsby et al., 1998; Padoani et al., 1998; Carlson et al., 1999; Cahn-Weiner et al., 2000; Bell-McGinty et al., 2002; Cahn-Weiner et al., 2002), particularly in cognitively impaired people. For example, Greiner et al., (1996), showed that adults older than 75 years with a Mini-Mental State Examination (MMSE) score $<27$ had twice the risk of losing their independence in one or more activities of daily living, such as bathing, dressing, and eating independently, after one year, compared to those with a higher level of cognitive performance. Bell-McGinty et al. (2002) reported similar findings. In their study of 50 older people, most of whom had impaired cognitive functioning, these authors showed that performance on tests of executive functioning was associated with the individual dependence in activities of daily living, such as management of personal finance. Such studies have tended to focus on older adults with mild cognitive impairment or neurodegenerative diseases (Richardson et al., 1995; BellMcGinty et al., 2002) or used a rather broad cognitive measure (i.e. MMSE score (Folstein et al., 1975)) (Gill et al., 1997; Grigsby et al., 1998; Padoani et al., 1998).

With respect to the measurement of cognitive performance in healthy elderly, there is ample evidence that cognitive rating scales such as the MMSE are too insensitive to evaluate performance on specific cognitive domains, and thus cannot be used to determine whether specific cognitive domains are affected (MacKenzie et al., 1996). Adequate performance in the domain of executive functions seems particularly relevant in this respect, because it enables a person to state and perform goals, deal with novelty, solve problems, adapt to unexpected circumstances, and perform multiple tasks (Lezak, 1995). If a person's executive functioning is inadequate, he/she will probably experience difficulties in performing multiple activities in daily life, such as managing a home, finances, or even taking medication, difficulties which adversely affect the functional status of that person.

Our aim was to investigate the cross-sectional and longitudinal relation between important cognitive domains (i.e. memory performance, executive functioning, and speed of information processing) and functional status in a large healthy sample of adults aged 60 years and older. We expected that executive functioning would be most strongly associated with functional status.

\section{METHODS}

\section{Participants}

The data used in the present study were derived from the Maastricht Aging Study, a longitudinal study examining determinants and consequences of differences in normal cognitive aging. Participants were recruited from a collaborating network of family practices (the Registration Network Family Practices) (Metsemakers et al., 1992). All participants were between 24 and 81 years of age, and were at the moment of inclusion without medical conditions known to interfere with normal cognitive function (e.g. dementia, mental retardation, and cerebrovascular pathology). The study population was stratified for age group, sex, and general ability. In the baseline period between 1993 and 1995 (Wave 1), 1,823 people underwent a cognitive and physical examination, (Jolles et al., 1995). About three years later (Wave 2), all people who were 50 years or older at the first examination $(n=1,069)$ were invited to participate in a re-assessment of their neuropsychological functioning. Because of refusal $(n=138)$, death $(n=50)$, loss to follow-up $(n=43), 838$ persons $(78 \%)$ were actually tested. Six years after the baseline measurements (Wave 3), all participants were again invited for a neuropsychological examination. At Wave $3,1,376$ participants of the 1,823 persons assessed at baseline $(74 \%)$, were actually tested. Four hundred forty-seven people (24\%) dropped out. Main reasons for dropping out were refusal $(n=275)$, death $(n=116)$, loss to follow-up $(n=37)$, or unspecified reasons $(n=19)$. For the present study, only data for participants aged 60 years or older were used. Data for participants with clinically verified major depression or dementia at three- or six-year follow-up were excluded from further analyses $(n=12,1.8 \%)$. The local medical ethics committee approved the MAASstudy and all participants gave their informed consent.

\section{Cognitive variables}

Many studies have shown that the first cognitive changes associated with aging are observed in the domains of memory functioning, executive functioning, and speed of information processing (e.g. Jolles, 1986; Salthouse, 1992). In addition, tests that draw on these domains have been shown to be sensitive to subtle changes in health (Houx et al., 1993; Van Boxtel et al., 1998; Bosma et al., 2000; Van Boxtel et al., 2000). For these reasons, these tests were used in this study.

The Stroop Colour-Word Test (SCWT) is a measure of selective attention and speed of information processing. This test involves three cards displaying 
100 stimuli each (Stroop, 1935; Houx and Jolles, 1993). The first card contains colour words printed in black ink, which have to be read aloud. The second card contains coloured patches, which have to be named. The last card displays colour names printed in incongruously coloured ink. Participants are instructed to name the ink colour of the printed words. By subtracting the time needed for the last part from the mean score of the first and second parts, an interference score can be calculated. This interference score is a measure of inhibition of a habitual response, which can be considered an aspect of executive functioning.

The Concept Shifting Task (CST) is a modified version of the Trial Making Test (Vink and Jolles, 1985) and is used to measure simple cognitive speed and cognitive flexibility. It consists of three parts. On each test sheet, 16 small circles are grouped in a larger circle. The smaller circles contain numbers, letters or both, appearing in a fixed random order. Participants are requested to cross out the items in the right order. In the last part, participants have to alternate between numbers (1-8) and letters (A-H). The scores correspond to the time needed to complete each trial. The difference between the last part and the mean score of the first and second parts is considered to reflect the additional time needed to shift between both sets of stimuli.

Intentional learning and verbal memory functioning were measured using the Visual Verbal Learning Test (VVLT) (Brand and Jolles, 1985). Fifteen monosyllabic words are presented one after another and subjects are asked to recall as many words as possible. This procedure is repeated five times. To preclude ceiling effects that may become apparent in the last two trails, the total score of the first three trails is used as dependent variable. After 20 min, delayed recall is tested.

Cognitive compound scores. Selected raw scores for cognitive tasks were clustered in three domains (sensorimotor speed, memory, and executive functioning) to yield compound cognitive scores. This was done to reduce the number of cognitive variables, while improving the robustness of the underlying cognitive construct (Lezak, 1995). Raw scores were transformed to $Z$-scores in the total group of participants that were selected in this study. The average was calculated of the Z-transformed scores that were included in a compound index. The memory compound score included the immediate and delayed recall of the VVLT. The sensorimotor speed compound score was derived from the first and second subtask of the SCWT and CST. The executive functioning compound score was calculated using the interference scores of the SCWT and
CST. The signs of the sensorimotor speed and executive functioning compound scores were inverted to make them reflect above average performance when positive and below average performance when negative (Van Boxtel et al., 1998).

\section{Functional status}

Functional status was measured using the SF-36 questionnaire, which contains 36 multiple-choice questions (Ware and Sherbourne, 1992). The SF-36 is coded into eight scales: physical functioning, social functioning, role limitations due to physical problems, role limitations due to emotional problems, general mental health, vitality, bodily pain, and general health perceptions. Each scale can range from 0 (lowest level of functioning) to 100 (highest level). These eight scales can be summarized into physical (PCS) and mental components summary measures (MCS) (Ware et al., 1994). Low scores imply a low level of functioning and the average of this score in the general US population is 50 (Ware et al., 1995). At the baseline measurement, the SF-36 was administered to two out of four participant panels only $(n=300$ in age 60 and older group). At Wave 2, nearly all participants in this age range filled in the SF-36 $(n=485,92 \%)$. At Wave 3, 386 persons filled in the SF-36.

\section{Other measures}

Age, sex, and level of education were considered potential confounders. Level of education was indexed on an eight-point ordinal scale: $1=$ primary education, $2=$ lower vocational education, $3=$ intermediate general secondary education, $4=$ intermediate vocational education, $5=$ higher general secondary education/ university preparatory education, $6=$ higher vocational preparatory education, $7=$ higher professional education, 8 = university education (De Bie, 1987).

\section{Data analysis}

To maximize the number of observations and acquire the highest power, cross-sectional analyses were based on available data at Wave 2 and the longitudinal analyses included data from Wave 2 and Wave 3. Means and standard deviations of the summary scores of the SF-36 were computed and compared between Wave 2 and 3, using paired $t$-tests. Associations between the cognitive compound scores at Wave 2 and the SF-36 summary score at Wave 2 and 3 were first examined with correlation analysis (Pearson's $r$ ). Subsequently, linear regression analysis was performed 
in order to analyse whether cognitive compound scores were cross-sectionally related to SF-36 summary scores. These analyses were adjusted for age, sex, and educational level. Next, the cognitive compound scores were analysed as predictors of a change in SF-36 summary scores three years later, again using linear regression analysis adjusted for age, sex, educational level, duration of follow-up interval, and SF-36 summary score at baseline. All analyses were performed using SPSS for Macintosh program series, version 10 (SPSS-Inc., Chicago, IL), with a $p$-level of 0.05 .

\section{RESULTS}

The PCS decreased from 46.7 to 44.9 after three years $(t=4.402, p<0.01)$, however, the MCS showed no change $(t=0.52, p=0.60)$. The three cognitive compound scores at the three-year follow-up were significantly correlated with the PCS at three-year followup (zero-order Pearson's $r$ for sensorimotor speed, memory, and executive functioning were $0.24,0.13$, and 0.25 , respectively) and again at the six-year follow-up (Pearson's $r$ for sensorimotor speed, memory, and executive functioning were $0.24,0.11$, and 0.20 , respectively). A different pattern was observed for the MCS. The three cognitive measures at the three-year follow-up were correlated with MCS at the same time point (sensorimotor speed: 0.21 ; memory: 0.10 ; executive functioning: 0.13 ), but not at the six-year follow-up (sensorimotor speed: 0.09 ; memory: 0.08 ; executive functioning: 0.06, all $p>0.05$ ).

Although not consistently evident for all cognitive summary scores, overall cognitive functioning was significantly related with both summary scores of the SF-36 in the cross-sectional regression analyses (Table 1). Higher scores on the cognitive compound measures were associated with higher scores on the
SF-36, even after adjusting for age, educational level, and sex. The strongest associations were between sensorimotor speed and executive functioning compound scores and SF-36 scales. These results are based on Wave 2. A similar pattern of results was found when the cross-sectional analyses were based on the baseline measurement or the Wave 3 measurement (results not tabulated).

Cognitive functioning was not associated with SF36 summary scores three- or six-years later (Table 1). Thus, older persons with good cognitive functioning at Wave 2 did not experience less decline on SF-36 scores (between Wave 2 and 3) compared with persons with poor cognitive function at Wave 2, independent of their baseline SF-36 score. Essentially the same results were found when the longitudinal analyses were repeated in the smaller group that was available from baseline to six-year follow-up (results not tabulated).

\section{DISCUSSION}

The aim of this study was to investigate whether cognitive functioning was related to functional status in older healthy adults. The cross-sectional findings indicated that cognitive performance was associated with functional status. Individuals with a low level of cognitive functioning had a lower functional status than individuals with a high level of cognitive functioning. The question whether cognitive performance has predictive power for functional decline was answered in the negative: low cognitive performance at baseline did not predict more functional decline three or six years later.

The cross-sectional relationship between cognitive and functional status variables has been reported earlier. It has been argued that this association can be explained, at least in part, by the presence of depressive

Table 1. Cross-sectional and longitudinal association (standardised regression coefficients) between cognitive functioning and three-year change in SF-36 summary scores

\begin{tabular}{|c|c|c|c|c|}
\hline & \multicolumn{2}{|c|}{ Cross sectional analyses } & \multicolumn{2}{|c|}{ Longitudinal analyses } \\
\hline & PCS & MCS & PCS & MCS \\
\hline & $\beta$ & $\beta$ & $\beta$ & $\beta$ \\
\hline Sensorimotor speed & $0.15^{* * *}$ & $0.11 * *$ & 0.01 & 0.04 \\
\hline Memory & 0.06 & $0.20 *$ & 0.05 & 0.01 \\
\hline Executive functioning & $0.16^{* * *}$ & $0.13^{*}$ & 0.03 & 0.01 \\
\hline
\end{tabular}

${ }^{*} p<0.05 ; * * p<0.01$.

$\mathrm{PCS}=$ physical component scale; $\mathrm{MCS}=$ mental component scale.

Note: Cross-sectional analyses were adjusted for age, sex and educational level. Longitudinal analyses were adjusted for age, sex and educational level, length of follow-up interval and cognitive functioning at baseline. 
symptoms, because depression or depressive symptoms are related to cognitive functions, notably memory, attention, and executive disorders (Burt et al., 1995; Austin et al., 2001; Den Hartog et al., 2003). In an earlier study, SF-36 scores were lower in depressed patients than in non-depressed controls (Doraiswamy et al., 2002). We therefore performed additional post hoc regression analyses in which depressive symptomatology, measured with the depression scale of the SCL-90 (Arrindell and Ettema, 1986) was controlled for. The cross-sectional relation between the PCS and the executive compound score was attenuated, but still significant after adjusting for depressive symptoms $(p<0.01)$. However, the relations between the MCS and the three cognitive domains and that between the PCS and sensorimotor speed were no longer significant, after adjusting for the number of depressive symptoms. Thus, depressive symptomatology may act as a confounder in the relation between cognitive functioning and functional status, but does not explain the crosssectional relation between executive functioning and SF-36 PCS

The population investigated in this study consisted of community dwelling older adults. These participants functioned at a normal level with respect to functional status as well as cognitive functioning. Therefore it was not surprising that the results of the present study demonstrated a small decrease in functional status over a three-year interval. It could be argued that a longer time lag and therefore a larger decrease in functional status may be needed to demonstrate a longitudinal association between cognitive functioning and functional status. Or a reverse causation (i.e. functional status as a predictor of cognitive decline) may be present.

It is possible that attrition at Wave 3 may have biased the longitudinal results. Attrition is a problem in longitudinal aging research, because sick, frail and poorly performing individuals tend to leave a study, yielding an elite sub-set of healthy, well-performing individuals. In our study, participants who dropped out of the study scored lower on cognitive measures and on the summary scores of the SF-36 compared to participants who did not dropped out of the study. This implies that the participants that were assessed at the follow-up measurements were indeed characterized by a higher level of functioning. In order to control for this attrition effect, we used several imputation strategies (Tabachnick and Fidell, 2001). First, missing values were replaced by hypothetical followup scores for the drop-outs using predicted scores from regression model for SF-36 scores. Thus, the SF-36 score at follow-up was the dependent variable and the following covariates were included: the baseline score, age, education and sex. The resulting regression model was then used to compute predicted scores for the drop outs. Based on this expanded dataset, linear regression analysis again revealed that cognitive functioning was not associated with three-year changes in the SF-36 summary scores (for all statistical tests: $\beta<0.038 ; p>0.341$ ). Using a more conservative imputation method, the SF-36 missing values at Wave 3 were replaced by the individual score at Wave 2 minus 1 standard deviation. The regression results again showed no longitudinal relationship between cognitive functioning and SF-36 scores three years later (for all statistical tests: $\beta<0.068$; $p>0.146)$. Thus, replacing the missing data of the drop outs by hypothetical data did not influence the overall pattern of results, which limits the probability that attrition substantially biased our findings.

Comparison of the associations between different cognitive functions showed that the strongest crosssectional relation was that between functional status and executive functioning. These findings are in line with previous cross-sectional studies that focused on (I)ADL, which have shown that performance on tests of executive functioning is more strongly related to functional impairment than other cognitive functions, including memory, language, visuospatial skills, and psychomotor speed (Grigsby et al., 1998; Carlson et al., 1999; Cahn-Weiner et al., 2000; Bell-McGinty et al., 2002; Cahn-Weiner et al., 2002). This could be taken as evidence to support the importance of executive functions to functional status, because these functions involve relatively complex behaviour, including activities related to planning, problem solving, anticipation of possible consequences of an intended course of action, and inhibition of irrelevant information (Lezak, 1995).

In conclusion, poor cognitive performance, and especially poor executive functioning, was related to poor functional status at the actual moment of testing. This association could be mediated by secondary factors, such as depressive symptomatology or life events, since cognitive functioning did not prove to be predictive of functional status three or six years later. The practical implication is that, in clinical practice, neuropsychological findings can indeed contribute to answering questions concerning the current functional status of an older person. Alternately, it is worthwhile to stress that inferences from neuropsychological assessment for functional status in the future are not valid in a normal aging population and may be influenced by an underlying depression or a bias due to negative affectivity. 


\section{ACKNOWLEDGEMENT}

This study was part of a research program funded by the Dutch Research Council (NWO, grant: 014-91047). In addition, the study was funded in part by a grant from the Dutch Ministries of Education and Health and Welfare via the Steering Committee for Gerontological Research (NESTOR) and from the Dutch Research Council.

\section{REFERENCES}

Arrindell WA, Ettema JHM. 1986. SCL-90. Een multidimensionele psychopathologie indicator (The SCL-90. A multidimensional instrument for the assessment of psychopathology). Swets \& Zeitlinger: Lisse.

Austin MP, Mitchell P, Goodwin GM. 2001. Cognitive deficits in depression: possible implications for functional neuropathology. Br J Psychiatry 178: 200-206.

Barth JT, Pliskin N, Axelrod B, et al. 2003. Introduction to the NAN 2001 Definition of a Clinical Neuropsychologist. NAN Policy and Planning Committee. Arch Clin Neuropsychol 18(5): 551555.

Bell-McGinty S, Podell K, Franzen M, et al. 2002. Standard measures of executive function in predicting instrumental activities of daily living in older adults. Int J Geriatr Psychiatry 17(9): 828-834.

Bosma H, Van Boxtel MP, Ponds RW, et al. 2000. Pesticide exposure and risk of mild cognitive dysfunction. Lancet 356(9233): 912-913.

Brand N, Jolles J. 1985. Learning and retrieval rate of words presented auditory and visually. J Gen Psychol 112(2): 201-210.

Burt DB, Zembar MJ, Niederehe G. 1995. Depression and memory impairment: a meta-analysis of the association, its pattern, and specificity. Psychol Bull 117(2): 285-305.

Cahn-Weiner DA, Boyle PA, Malloy PF. 2002. Tests of executive function predict instrumental activities of daily living in community-dwelling older individuals. Appl Neuropsychol 9(3): 187-191.

Cahn-Weiner DA, Malloy PF, Boyle PA, et al. 2000. Prediction of functional status from neuropsychological tests in communitydwelling elderly individuals. Clin Neuropsychol 14(2): 187-195.

Carlson MC, Fried LP, Xue QL, et al. 1999. Association between executive attention and physical functional performance in community-dwelling older women. J Gerontol B Psychol Sci Soc Sci 54(5): S262-S270.

De Bie SE. 1987. Standaardvragen 1987-voorstellen voor uniformering van vraagstellingen naar achtergrondkenmerken en interviews (Toward a standardization of questions concerning demographic variables in population studies). Leiden University Press: Leiden.

Den Hartog HM, Derix MMA, Van Bemmel B, et al. 2003. Cognitive functioning in young to middle-aged unmedicated outpatients with major depression: testing the effort and cognitive speed hypotheses. Psychol Med 33(8): 1443-1451.

Doraiswamy PM, Khan ZM, Donahue RM, et al. 2002. The spectrum of quality-of-life impairments in recurrent geriatric depression. J Gerontol A Biol Sci Med Sci 57(2): M134-M137.

Folstein MF, Folstein SE, McHugh PR. 1975. 'Mini Mental State'. A practical method for grading the state of patients for the clinician. J Psychiatric Res 12: 189-198.
Gill TM, Williams CS, Richardson ED, et al. 1997. A predictive model for ADL dependence in community-living older adults based on a reduced set of cognitive status items. J Am Geriatr Soc 45(4): 441-445.

Greiner PA, Snowdon DA, Schmitt FA. 1996. The loss of independence in activities of daily living: the role of low normal cognitive function in elderly nuns. Am J Public Health 86(1): 62-66.

Grigsby J, Kaye K, Baxter J, et al. 1998. Executive cognitive abilities and functional status among community-dwelling older persons in the San Luis Valley Health and Aging Study. J Am Geriatr Soc 46(5): 590-596.

Houx PJ, Jolles J. 1993. Age-related decline of psychomotor speed: effects of age, brain health, sex, and education. Percept Mot Skills 76: 195-211.

Houx PJ, Jolles J, Vreeling FW. 1993. Stroop interference: aging effects assessed with the Stroop Color-Word test. Exp Aging Res 19: 209-224.

Jolles J. 1986. Cognitive, emotional and behavioral dysfunctions in aging and dementia. Prog Brain Res 70: 15-39.

Jolles J, Houx PJ, Van Boxtel MPJ, et al. (eds). 1995. Maastricht Aging Study: Determinants of Cognitive Aging. Neuropsych Publishers: Maastricht.

Lezak MD. 1995. Neuropsychological Assessment. Oxford University Press: New York.

MacKenzie DM, Copp P, Shaw RJ, et al. 1996. Brief cognitive screening of the elderly: a comparison of the Mini-Mental State Examination (MMSE), Abbreviated Mental Test (AMT) and Mental Status Questionnaire (MSQ) Psychol Med 26(2): 427-430.

Metsemakers JFM, Höppener P, Knottnerus JA, et al. 1992. Computerized health information in the Netherlands: a registration network of family practices. Br J Gen Pract 42: 102-106.

Padoani W, Dello Buono M, Marietta P, et al. 1998. Cognitive performance and quality of life in a sample of 220 nondemented elderly people. Arch Gerontol Geriatr 6: 373-380.

Richardson ED, Nadler JD, Malloy PF, et al. 1995. Neuropsychologic prediction of performce measures of daily living skills in geriatric patients. Neuropsychol 9(4): 565-572.

Salthouse TA. 1992. Mechanisms of Age-Cognition Relations in Adulthood. Hillsdale, NJ: Lawrence Erlbaum Associates: Hillsdale, NJ.

Stroop JR. 1935. Studies of interference in serial verbal reactions. $J$ Exp Psychol 18: 643-662.

Tabachnick BG, Fidell LS. 2001. Using multivariate statistics. Allyn and Bacon: Boston, MA.

Van Boxtel MPJ, Buntinx F, Houx PJ, et al. 1998. The relation between morbidity and cognitive performance in a normal aging population. J Gerontol: Med Sci 53A(2): M146-M154.

Van Boxtel MPJ, Van Beijsterveldt T, Houx PJ, et al. 2000. Mild hearing impairment can reduce verbal memory performance in a healthy adult population. J Clin Exp Neuropsychol 22(1): $147-154$.

Vink M, Jolles J. 1985. A new version of the Trail-Making Test as an information processing task. J Clin Neuropsychol 7: 162.

Ware JE, Sherbourne CD. 1992. The MOS 36-item short-form health survey (SF-36): I. conceptual framework and item selection. Med Care 30(6): 473-483.

Ware JE, Kosinski M, Bayliss MS, et al. 1995. Comparison of methods for the scoring and statistical analysis of SF-36 health profile and summary measures: summary of results from the Medical Outcomes Study. Med Care 33(Suppl. 4): AS264-AS279.

Ware JE, Kosinski M, Keller SD. 1994. SF-36 Physical and Mental Summary Scales: A User's Manual. The Health Institute: Boston, MA. 